\title{
IMPACT OF CONSUMER ATTITUDES ON SUSTAINABILITY PRACTICES WITHIN THE PAPER INDUSTRY: THE MODERATING ROLE OF DIGITAL MEDIA
}

\author{
Antony Paulraj, University of Southern Denmark \\ Steven Williamson, University of North Florida, Jacksonville, Florida, USA
}

dx.doi.org/10.18374/JABE-13-1.12

\begin{abstract}
Consumer knowledge about the environmental impacts of paper as well as digital products is a key element in driving their perceptions regarding the environmental sustainability of these industries. We inherently believe that consumers' primary understanding about these complementary products in addition to the sustainable practices within the underlying industries could have a complex "interaction" effect on their perceptions about the sustainability of these industries. Therefore, our research focuses on studying the effects of consumer knowledge of environmental practices on the sustainability performance of the paper industry. Specifically, we study the impact of consumer knowledge on destruction of trees, sustainable raw material usage and sustainable production processes, as well as the environmental impact of digital media on the sustainability performance of the paper industry. Using data collected from 504 consumers across the United States (US), we hypothesize and test a number of direct and moderating effects between these constructs. Our results provide persuasive support for the considerable role that consumer knowledge could play in perceptions relating to the paper industry's sustainability performance. We also offer implications for future research and practice within the paper industry.
\end{abstract}

Keywords: Consumer Perceptions, Paper Industry, Sustainability Performance, Tree and Energy Usage, Environmental Impact of Digital Media, Structural Equation Modeling 